\title{
Seismic Analysis of Vertical Irregular RC Building with Stiffness and Setback Irregularities
}

\author{
Oman Sayyed ${ }^{1}$, Suresh Singh Kushwah ${ }^{2}$, Aruna Rawat ${ }^{3}$ \\ ${ }^{I}$ (Post Graduate student, Department of Civil Engineering, University Institute of Technology (RGPV), India) \\ ${ }^{2}$ (Professor\& HOD, Department of Civil Engineering, University Institute of Technology (RGPV), India) \\ ${ }^{3}$ (Asst. Prof. Department of Civil Engineering, University Institute of Technology (RGPV), India)
}

\begin{abstract}
The performance of a high rise building during strong earthquake motions depends on the distribution of stiffness, strength and mass along both the vertical and horizontal directions. If there is discontinuity in stiffness, strength and mass between adjoining storeys of a building then such a building is known as irregular building. The present study focuses on the performance and behavior of regular and vertical irregular $G+10$ reinforced concrete $(R C)$ buildings under seismic loading. Two types of vertical irregularities namely stiffness and setback are considered in this study. Total eight regular and irregular buildings are modeled and seismic analysis is carried out using response spectrum analysis (RSA) method. Different seismic responses like storey displacement, storey drift, overturning moment, storey shear force, and storey stiffness are obtained. By using these responses, a comparative study has been made between regular and irregular buildings. The result remarks the conclusion that, a building structure with stiffness and setback irregularity provides instability during seismic loading. To control the instability, a proportionate amount of stiffness is beneficial in RC building.
\end{abstract}

Keywords: Response spectrum analysis, Storey displacement, Storey drifts, Setback, Vertical irregularity.

\section{Introduction}

The failure in the multistorey building due to seismic loading generally initiates at the location where there is a weakness in the building. This weakness causes deterioration of the building which results in structural collapse. This weakness mostly occurs due to the presence of irregularities in stiffness, strength and mass in a building. These irregularities are classified into two forms namely plan irregularity and vertical irregularity. As per IS 1893:2002 (part I) vertical irregularities are classified as follows:

1) Stiffness irregularity:

a) Soft storey: A soft storey is one in which the lateral stiffness is less than 70 percent of that in the storey above or less than 80 percent of the average lateral stiffness of the three storeys above

b) Extreme soft storey: A extreme soft storey is one in which the lateral stiffness is less than 60 percent of that in the storey above or less than 70 percent of the average stiffness of the three storeys above.

2) Mass irregularity: Mass irregularity shall be considered to exist where the seismic weight of any storey is more than 200 percent of that of its adjacent storeys.

3) Vertical geometric irregularity: Vertical geometric irregularity shall be considered to exist where the horizontal dimension of the lateral force resisting system in any storey is more than 150 percent of that in its adjacent storey.

4) In plane discontinuity in vertical elements resisting lateral force: An in-plane offset of the lateral force resisting elements greater than the length of those elements.

5) Discontinuity in capacity: A weak storey is one in which the storey lateral strength is less than 80 percent of that in the storey above.

\section{Literature Review}

Shaikh and Deshmukh (2013) performed linear static \& dynamic analysis of G+10 vertically irregular building as per IS 1893:2002 (part I) provisions. The building was modeled as a simplified lump mass model having stiffness irregularity at fourth floor. The response parameters like storey drift, storey deflection and storey shear of the building were evaluated. The results show that, stiffness irregularity causes instability in the building and attracts huge storey shear.

Mahesh and Rao (2014) studied the behavior of regular and irregular G+11 residential building under seismic motion. They considered different seismic zones and three different types of soils namely hard, medium and soft. The analysis was done by two softwares ETABS and STAAD PRO.

Bansal and Gagandeep (2014) carried out response spectrum analysis (RSA) and time history analysis (THA) of vertically irregular RC building frames. They considered mass, stiffness and vertical geometric 
irregularity. They found that mass irregular building experience larger base shear than similar regular building. The stiffness irregular building experienced lesser base shear and has larger inter storey drifts.

Rana and Raheem (2015) studied the performance of vertical geometric irregular RC frame structures under seismic motion. A comparative study between one regular frame \& four irregular building frames were carried out. Various seismic responses like shear force, bending moment, storey drift, storey displacement etc. were obtained. It was concluded that regular building frames possess very low shear force compared to setback irregular frames.

The objectives of the present study are (i) to study the performance and behavior of total eight regular and irregular RC buildings having stiffness and setback irregularity, (ii) to analyse all the G+10 RC buildings as per IS1893:2002 (part I) criteria using CSI ETABS 2015 software. Response spectrum analysis is carried out considering seismic zone $\mathrm{V}$ and medium soil strata in all the cases and (iii) to compare the responses like storey displacement, storey drift, overturning moment, storey shear force, and storey stiffness between the regular and vertical irregular buildings.

\section{Methodology}

In this study seismic anlysis of all the eight regular and irregular RC buildings has been carried out. Two types of vertical irregularities namely stiffness and setback are considered. The structural detail of regular building is shown in Table I.

Table I: Structural Detail of Regular Building Model

\begin{tabular}{|l|l|l|}
\hline Specification & For stiffness irregularity & For setback irregularity \\
\hline No. of Stories & G+10 & G+10 \\
\hline Storey height & $3 \mathrm{~m}$ & $3 \mathrm{~m}$ \\
\hline No. of bays in X and Y direction & 3 & 4 \\
\hline Spacing of frame in X and Y direction & $4 \mathrm{~m}$ & $4 \mathrm{~m}$ \\
\hline Grade of concrete & $\mathrm{M} 25$ & $\mathrm{M} 25$ \\
\hline Modulus of elasticity of concrete & $25 \times 10^{3} \mathrm{MPa}$ & $25 \times 10^{3} \mathrm{MPa}$ \\
\hline Thickness of slab & $0.125 \mathrm{~m}$ & $0.125 \mathrm{~m}$ \\
\hline Beam size & $0.45 \mathrm{~m} \times 0.30 \mathrm{~m}$ & $0.45 \mathrm{~m} \times 0.30 \mathrm{~m}$ \\
\hline Column size & $0.45 \mathrm{~m} \times 0.45 \mathrm{~m}$ & $0.45 \mathrm{~m} \times 0.45 \mathrm{~m}$ \\
\hline No. of modes used & 30 & 30 \\
\hline Damping ratio & $5 \%$ & $5 \%$ \\
\hline Seismic zone & $\mathrm{V}$ & $\mathrm{V}$ \\
\hline Response reduction factor (R) & 5 & 5 \\
\hline Soil type & Medium & Medium \\
\hline Zone factor (Z) & 0.36 & 0.36 \\
\hline Importance factor ( I) & 1 & 1 \\
\hline
\end{tabular}

\section{1) Stiffness irregularity:}

Four types of building models are analysed in this case: one regular building (B1) as shown in Fig. 1 and three irregular buildings namely ground storey, fourth storey and seventh storey as soft storey. These buildings are modeled as $\mathrm{G}+10$ storey having three bays in both the direction. The irregularity in the building is generated by increasing the height of the storey. Thus, the irregular storey has a height of $4.5 \mathrm{~m}$ as shown in Fig. 2 .

Stiffness of each column $=12 E I / L^{3}$

Therefore, stiffness of ground storey/stiffness of other storey $=(3 / 4.5)^{3}=0.3<0.7$

Hence as per IS 1893:2002 (part I) the building has stiffness irregularity.



Plan

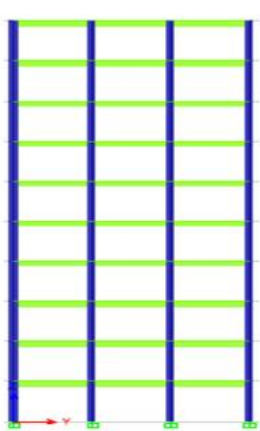

Elevation

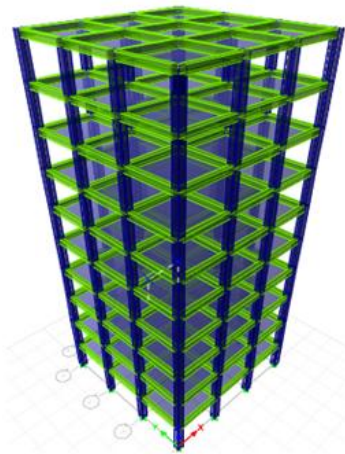

3D

Figure 1: Plan, elevation and 3D of regular building model (B1). 




Ground storey as soft storey (S1)

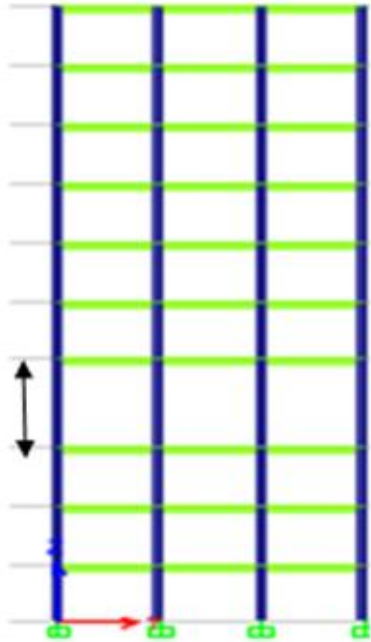

Fourth storey as soft storey (S2)

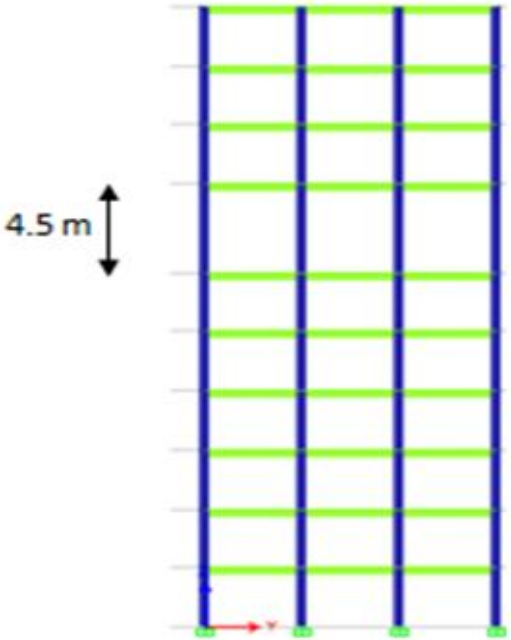

Seventh storey as soft storey (S3)

Figure 2: Elevation of stiffness irregular building models.

\section{2) Setback irregularity:}

Four types of building models are selected in this case: one regular building (B2) as shown in Fig. 3 and three irregular buildings having setback irregularity in eighth, fifth and second storey along X-direction as shown in Fig. 4. These buildings are modeled as $\mathrm{G}+10$ storey having four bays in both the direction.

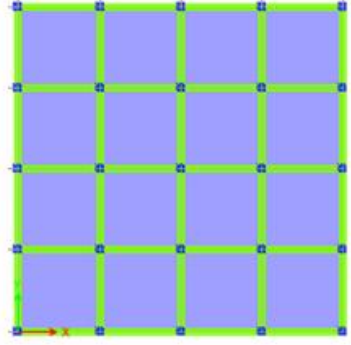

Plan



Elevation

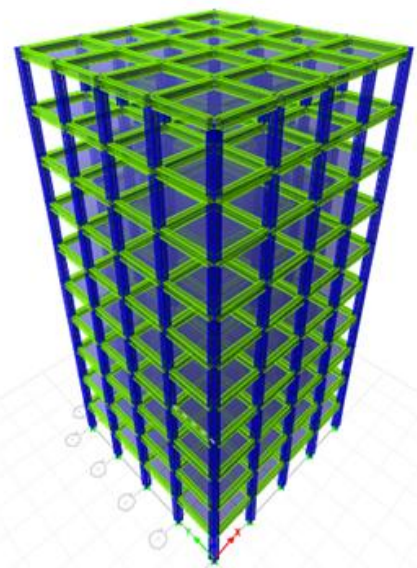

$3 \mathrm{D}$

Figure 3: Plan, elevation and 3D of regular building model (B2).



Setback irregularity in $8^{\text {th }}$ storey (G1)



Setback irregularity in $5^{\text {th }}$ storey $(\mathrm{G} 2)$

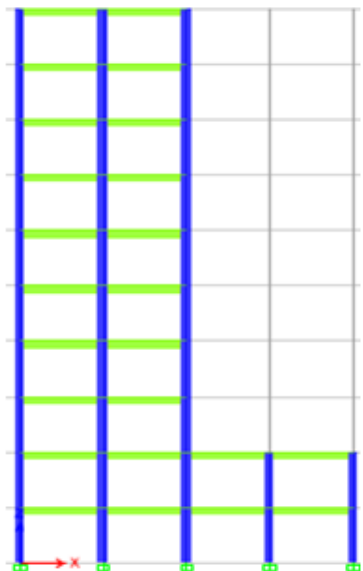

Setback irregularity in $2^{\text {nd }}$ storey $(\mathrm{G} 3)$

Figure 4: Elevation of setback irregular building models. 


\section{Stiffness irregularity:}

\section{Results and Discussion}

The storey displacement curve shown in Fig. 5 concludes that, stiffness irregular buildings undergo much more displacement as compare to regular building. In case of model S1 the displacement in the ground storey is 1.5 times more than that of regular building model B1, and it taper off towards the top of the building. A sudden change in the slope of storey displacement curve has been observed with change in stiffness of a storey. The storey drift curve as shown in Fig. 6 indicates that, due to stiffness irregularity there is sudden extreme change in storey drift as compared to the regular building.

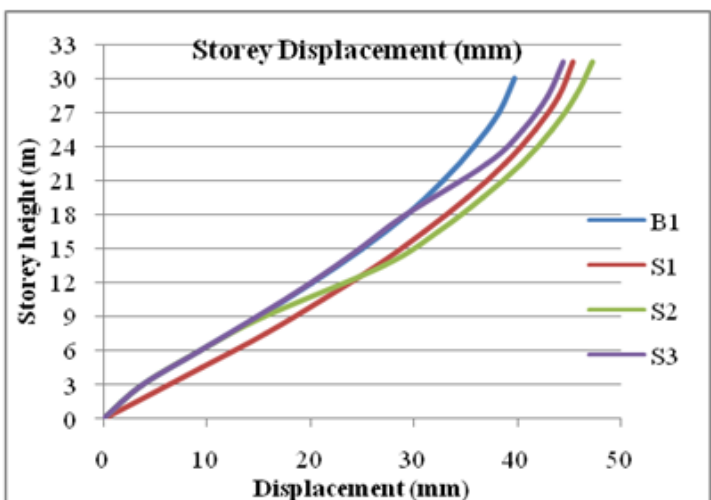

Figure 5: Storey displacement

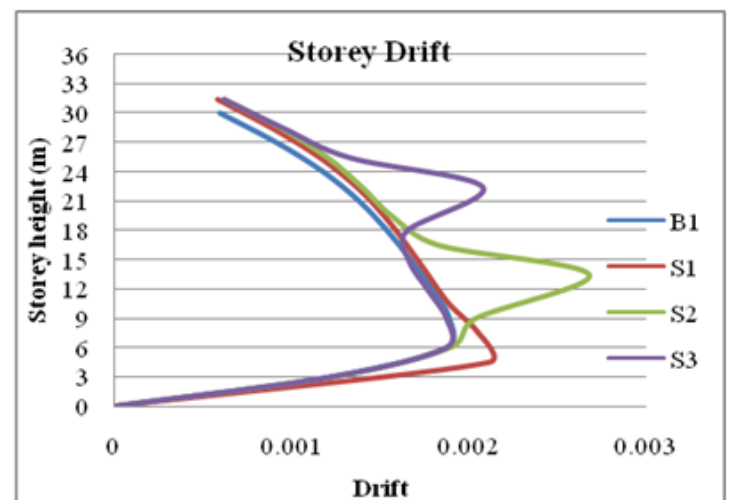

Figure 6: Storey drift

The overturning moment and storey shear force in case of irregular buildings are slightly greater than that of regular building as shown in Figs. 7 and 8, respectively. Both of these parameters are maximum in case of model S2 in the ground storey of the building. A moderate increase in the slope of the shear force curve has been observed in the irregular storeys.

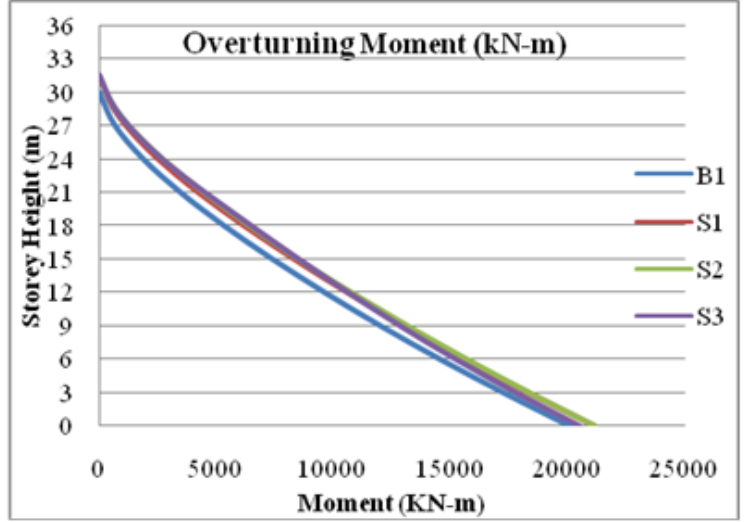

Figure 7: Overturning moment

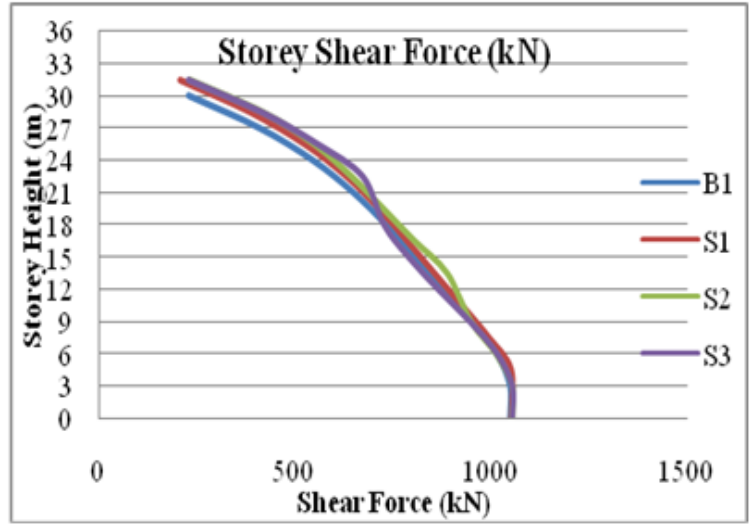

Figure 8: Storey shear force

A sudden extreme change in the stiffness of the building has been observed at the irregular storeys as shown in Fig. 9.

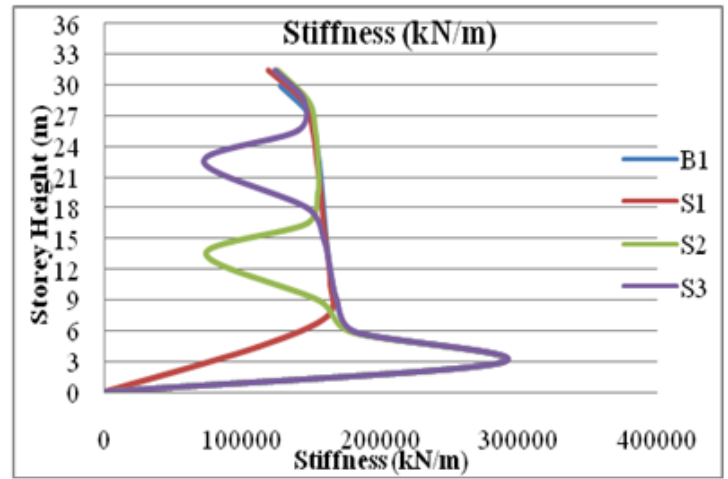

Figure 9: Storey stiffness 


\section{Setback irregular building:}

The storey displacement curve shown in Fig. 10 indicates that, the top node displacement in setback irregular buildings is more than that of regular building, except in case of model G1. In model G1, the displacement is more in lower storeys but it taper off towards the top of the building. This behavior may be due to the decrease in mass of the building because of setback. In case of model G2, a sudden change in slope of the displacement curve due to setback at fifth storey has been observed, but its top node displacement is $25 \%$ more than that of model B2. At second storey, displacement in model G3 is about $22 \%$ less than that of model B2, but its top node displacement is $12 \%$ more than that of model B2. From Fig. 11 it can be observed that there is a sudden extreme change in storey drift due to setback. The slope of the storey drift curve first decreases before setback, and then increases suddenly just after setback.



Figure 10: Storey displacement

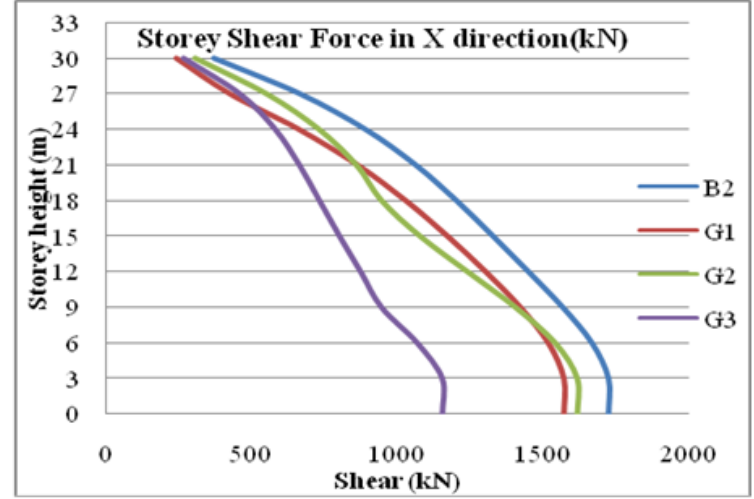

Figure 11: Storey drift

The overturning moment and storey shear force in case of setback irregular buildings are less than that of regular building as shown in Fig. 12 and 13, respectively.

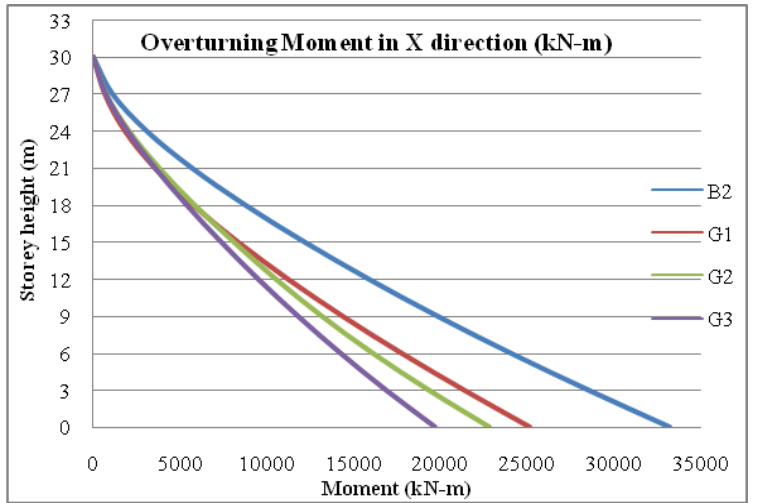

Figure 12: Overturning moment

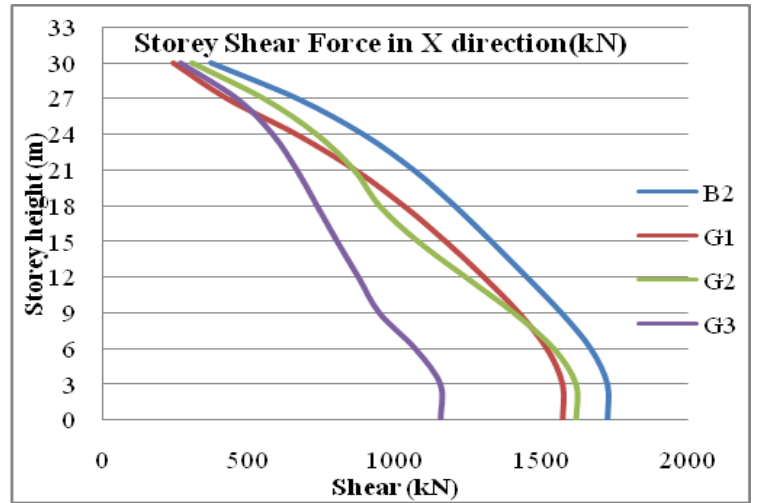

Figure 13: Storey shear force

From the storey stiffness curve as shown in Fig. 14, it has been observed that, as the amount of setback increases the storey stiffness decreases.

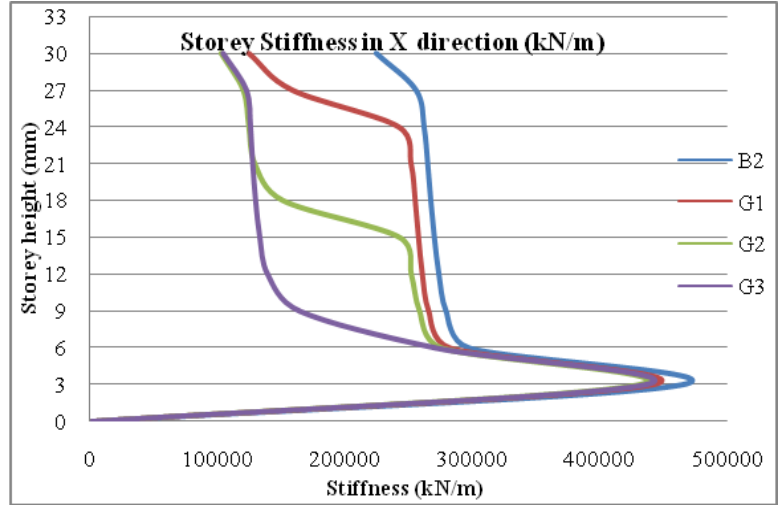

Figure 14: Storey stiffness 


\section{Conclusion}

After studying the performance and behavior of regular and vertical irregular G+10 reinforced concrete buildings under seismic loading, the following conclusions are drawn.

1. The storey displacement in case of stiffness irregular buildings is more than that of the regular building. Considering storey displacement, ground soft storey (S1) is the most critical case because its displacement is 1.5 times more than that of regular building (B1) in the ground storey. The result shows that the top node displacement in case of setback irregular buildings is more than that of the regular building, except in case of model G1.

2. In case of stiffness irregular buildings, storey drift is maximum at irregular storeys. Considering storey drift, model S2 is the most critical case. In setback irregular buildings, a sudden extreme change in storey drift due to setback has been observed.

3. In case of stiffness irregular buildings, the overturning moment and storey shear force in case of irregular buildings are slightly greater than that in regular building. A moderate increase in the slope of the shear force curve has been observed at the irregular storeys. In case of setback irregular buildings, the overturning moment and storey shear force are less than that of the regular building. As the amount of setback increases, the overturning moment decreases.

4. In case of stiffness irregular buildings, a sudden decrease in stiffness of the building has been observed at the irregular storeys. The results of setback irregular buildings show that, as the amount of setback increases the stiffness of the building decreases.

5. The analysis shows that the vertical irregularities widely affect the performance of a RC building under seismic loading. As far as possible these irregularities must be avoided, but if it has to be introduced they must be properly designed.

\section{References}

[1]. R Shaikh. and G. Deshmukh. "Seismic Response of Vertically Irregular RC Frame with Stiffness Irregularity at Fourth Floor", International Journal of Emerging Technology and Advanced Engineering. (Volume 3, Issue 8, Aug 2013), ISSN NO: $2250-2459$.

[2]. S. Mahesh and B. P. Rao. "Comparison of Analysis and Design of Regular and Irregular Configuration of Multi Storey Building in Various Seismic Zones and Various types of Soils using ETABS and STAAD”, International Journal of Mechanical and Civil Engineering. (Volume 11, Issue 6, Dec 2014), ISSN NO: 2278-1684.

[3]. H. Bansal and Gagandeep. "Seismic Analysis and Design of Vertically Irregular RC Building Frames", International Journal of Science and Research. (Volume 3, Issue 8, August 2014), ISSN NO: 2319-7064.

[4]. D. Rana and J. Raheem. "Seismic Analysis of Regular \& Vertical Geometric Irregular RCC Framed Building", International Research Journal of Engineering and Technology (Volume: 02, Issue 04, July-2015) ISSN NO: 2395-0056.

[5]. IS 1893:2002 (Part 1). "Indian Standard Criteria for Earthquake Resistant Design of Structures", Bureau of Indian Standards (BIS), New Delhi, India. 